\title{
Protein Phosphatase-Mediated Regulation of Protein Kinase C during Long-Term Depression in the Adult Hippocampus In Vivo
}

\author{
Edda Thiels, Beatriz I. Kanterewicz, Lauren T. Knapp, German Barrionuevo, and Eric Klann \\ Department of Neuroscience and Center for the Neural Basis of Cognition, University of Pittsburgh, Pittsburgh, \\ Pennsylvania 15260
}

\begin{abstract}
The neural substrates of learning and memory are thought to involve use-dependent long-term changes in synaptic function, including long-term depression (LTD) of synaptic strength. One biochemical event hypothesized to contribute to the maintenance and expression of LTD is decreased protein phosphorylation, caused by a decrease in protein kinase activity and/or an increase in protein phosphatase activity. We tested whether the activity of protein kinase $\mathrm{C}$ (PKC) decreases after the induction of LTD in area CA1 of the adult hippocampus in vivo, and then investigated the mechanism responsible for the LTD-associated alteration in PKC activity. We found that LTD was associated with a significant decrease in both autonomous and cofactordependent PKC activity. The decrease in PKC activity was prevented by NMDA receptor blockade and was not accompanied by a decrease in the level of either $\operatorname{PKC} \alpha, \beta, \gamma$, or $\zeta$. Western blot analysis with phosphospecific antibodies revealed that phos-
\end{abstract}

phorylation of Ser-657 on the catalytic domain of PKC $\alpha$ (Ser-660 on $\mathrm{PKC} \beta \mathrm{II})$ was decreased significantly after the induction of LTD, and that this dephosphorylation was prevented by the protein phosphatase inhibitor okadaic acid. The decrease in autonomous and cofactor-dependent PKC activity likewise was prevented by okadaic acid. These findings suggest that LTD in the adult hippocampus in vivo involves a decrease in PKC activity that is mediated, at least in part, by dephosphorylation of the catalytic domain of PKC by protein phosphatases activated after LTD-inducing stimulation. Our findings are consistent with the idea that protein dephosphorylation contributes to the expression of LTD.

Key words: long-term depression; protein kinase C; protein phosphatase; dephosphorylation; area CA1; learning and memory
The neural substrates of information processing and storage most likely involve activity-dependent long-term changes in synaptic strength. Two forms of synaptic plasticity induced by patterned activity in the afferent pathway and considered widely as models of learning and memory are long-term potentiation (LTP) and longterm depression (LTD) of synaptic strength (Bliss and Collingridge, 1993; Malenka, 1994; Martin et al., 2000). A critical element in the events hypothesized to underlie the induction and early expression of LTP and LTD is modification of protein phosphorylation (Bear and Malenka, 1994; Lisman, 1994; Schulman, 1994; Roberson et al., 1996). Specifically, LTP is thought to involve increased protein phosphorylation, an idea that is supported by findings of (1) increased protein kinase activity during LTP in hippocampus (Charriaut-Marlangue et al., 1991; Fukunaga et al., 1993; Klann et al., 1993), a forebrain structure demonstrated to play a critical role in memory function (Squire, 1992), (2) increased glutamate receptor phosphorylation in association with hippocampal LTP (Barria et al., 1997; Lee et al., 2000), (3) blockade of the induction and/or expression of hippocampal LTP by inhibition of basal protein kinase activity (Malinow et al., 1988, 1989; Malenka et al., 1989), and (4) alterations of LTP in hippocampus of mice deficient for one of various protein kinase genes (c.f., Chen and Tonegawa, 1997).

LTD, on the other hand, is thought to involve decreased protein phosphorylation, an idea supported by findings of (1) increased protein phosphatase activity during LTD in hippocampus (Thiels et al., 1998), (2) decreased glutamate receptor phosphorylation in association with hippocampal LTD (Lee et al., 1998, 2000), and (3) blockade of the induction and/or expression of hippocampal LTD

\footnotetext{
Received Feb. 18, 2000; revised June 16, 2000; accepted July 18, 2000.

This work was supported by National Institutes of Health Grants NS36180 (E.T.), NS34007 (E.K.), and NS24288 (G.B.). We thank Dr. Alexandra C. Newton for helpful suggestions.

Correspondence should be addressed to Edda Thiels, Department of Neuroscience 446 Crawford Hall, University of Pittsburgh, Pittsburgh, PA 15260. E-mail: thiels@bns.pitt.edu.

Copyright (c) 2000 Society for Neuroscience $0270-6474 / 00 / 207199-09 \$ 15.00 / 0$
}

by inhibition of protein phosphatase activity (Mulkey et al., 1993, 1994). Interestingly, the protein phosphatases whose activity was found to be increased during LTD, protein phosphatase 1 (PP1) and protein phosphatase 2A (PP2A) (Thiels et al., 1998), have been shown to dephosphorylate and regulate the activity of various protein kinases, including of protein kinases implicated in synaptic plasticity (Anderson et al., 1990; Dutil et al., 1994; Strack et al., 1997). Reduction of protein kinase activity caused by modification by protein phosphatases activated after LTD-inducing stimulation could contribute to and amplify protein dephosphorylation.

One of the protein kinases targeted by PP1 and PP2A and shown to play a role in synaptic plasticity is protein kinase $\mathrm{C}$ (PKC) (c.f., Roberson et al., 1996). Of particular relevance to the regulation of PKC during LTD are findings of proteolytic degradation of a permanently active isoform of $\mathrm{PKC}, \mathrm{PKM} \zeta$, after the induction of LTD in the immature hippocampus in vitro (Hrabetova and Sacktor, 1996). Our previous observations of an LTD-associated increase in PP1 and PP2A activity (Thiels et al., 1998), together with evidence for PKC regulation by these phosphatases (Dutil et al., 1994; Keranen et al., 1995; Bornancin and Parker, 1996, 1997; Lee et al., 1996; Sweatt et al., 1998) prompted us to investigate whether LTD in the adult hippocampus in vivo is associated with a change in PKC activity, and if so, whether the change in PKC activity results from dephosphorylation and/or proteolytic degradation of the kinase.

We herein report that LTD in the adult hippocampus in vivo is accompanied by a decrease in autonomous and cofactor-dependent $\mathrm{PKC}$ activity but not by a reduction in the level of either $\mathrm{PKC} \alpha, \beta$, $\gamma$, or $\zeta$. Additional experiments revealed an LTD-associated decrease in phosphorylation at Ser-657, an autophosphorylation site on the $\mathrm{C}$ terminus of PKC $\alpha$ (Ser-660 on PKC $\beta$ II). The LTDassociated decrease in autonomous and cofactor-dependent PKC activity as well as in phosphorylation at the autophosphorylation site were blocked by inhibition of okadaic acid (OA)-sensitive protein phosphatases. Taken together, these findings suggest that LTD in the adult hippocampus in vivo involves a decrease in PKC activity that is mediated, at least in part, by dephosphorylation of 
the catalytic domain of PKC by serine/threonine protein phosphatases activated after LTD-inducing stimulation.

Some of the electrophysiological results have been reported previously (Norman et al. 2000).

\section{MATERIALS AND METHODS}

Electrophysiology. Electrophysiological methods described previously (Thiels et al., 1994) were used for recordings from the hippocampus of anesthetized adult rats (Sprague Dawley, 250-350 gm). Briefly, field responses evoked by stimulation pulses $(20-500 \mu \mathrm{A} ; 100 \mu \mathrm{sec}$ duration) delivered to the dorsal commissural pathway were recorded in either st. pyramidale or st. radiatum of area CA 1 of the right dorsal hippocampus. Series of 10 test pulses $(0.1 \mathrm{~Hz})$ were delivered at 5-10 min intervals before and after paired-pulse stimulation, which consisted of three trains of 200 pairs of pulses with an interstimulus interval of $25 \mathrm{msec}$, an interpair interval of $2 \mathrm{sec}$, and an intertrain interval of $15 \mathrm{~min}$. The stimulation intensity for test and train pulses was set to produce a CA1 population spike amplitude $\sim 40 \%$ of maximum amplitude, as determined before the first series of test pulses. In some experiments, either D-2-amino-5phosphonovaleric acid (D-APV; $100 \mu \mathrm{M}$, dissolved in $150 \mathrm{mM} \mathrm{NaCl}$ ) or OA (5-10 $\mu \mathrm{M}$, dissolved in $0.1 \%$ dimethylsulfoxide) was administered by continuous pressure-ejection from a micropipette placed near the recording electrode in st. radiatum. Recorded waveforms were amplified, filtered $(0.1-10 \mathrm{kHz})$, digitized $(10 \mathrm{kHz})$, and stored on computer disk for later analysis of the amplitude of the CA1 population spike or the initial slope (1.0 msec after onset) of the population EPSP.

To determine PKC activity at various times after the induction of LTD animals were killed either 5, 35, or 65 min after termination of the third train of paired-pulse stimulation, and their right hippocampus was dissected out in the presence of cooled artificial CSF (in mM: $124 \mathrm{NaCl}, 5$ $\mathrm{KCl}, 1.25 \mathrm{NaH}_{2} \mathrm{PO}_{4}, 26 \mathrm{NaHCO}_{3}, 10$ dextrose, $1.5 \mathrm{MgCl}_{2}$, and $2.5 \mathrm{CaCl}_{2}$ ). A block of area CA1 $\left(\sim 1 \mathrm{~mm}^{3}\right)$ was excised from each the dorsal and the ventral portion of the hippocampus and placed in individual, coded vials on dry ice, which then were stored at $-70^{\circ} \mathrm{C}$ until biochemical analysis.

$P K C$ assays. Tissue samples were homogenized in ice-cold buffer $[50 \mathrm{~mm}$ Tris-HCl, pH 7.4, 1 mM EGTA, 1 mM EDTA, $10 \mu \mathrm{M}$ benzamidine aprotinin $(100 \mathrm{ng} / \mathrm{ml})$, leupeptin $(250 \mathrm{ng} / \mathrm{ml}), 2 \mathrm{~mm}$ sodium pyrophosphate, $4 \mathrm{~mm} p$-nitrophenylphosphate, and $1 \mathrm{~mm}$ sodium orthovanadate]. Protein concentrations in homogenates were determined using the method of Bradford (1976). Reaction mixtures (final volume, $50 \mu \mathrm{l}$ ) contained $5 \mu \mathrm{l}$ of homogenate, $20 \mathrm{~mm}$ Tris- $\mathrm{HCl}, \mathrm{pH} 7.4,10 \mathrm{~mm} \mathrm{MgCl}_{2}, 2 \mathrm{~mm}$ sodium pyrophosphate, leupeptin $(25 \mu \mathrm{g} / \mathrm{ml}), 10 \mu \mathrm{M}$ of the specific PKC substrate $\mathrm{NG}_{(28-43)}$, and $100 \mu \mathrm{M}\left[\gamma^{-32} \mathrm{P}\right] \mathrm{ATP}$. Assays were conducted in the presence of either EGTA (final concentration, $2.5 \mathrm{~mm}$ ) for the determination of autonomous activity or $\mathrm{Ca}^{2+}(100 \mu \mathrm{M}$ in the presence of $500 \mu \mathrm{M}$ EGTA) and lipid cofactors (final concentrations: phosphatidylserine, $320 \mu \mathrm{g} / \mathrm{ml}$; $s n$-1,2-dioctanoylglycerol, $30 \mu \mathrm{g} / \mathrm{ml}$ ) for the determination of total activity. Cofactor-dependent activity was determined by subtracting autonomous activity from total activity. Reactions were performed for $2 \mathrm{~min}$ at $37^{\circ} \mathrm{C}$. ${ }^{32} \mathrm{P}$ incorporation into $\mathrm{NG}_{(28-43)}$ was determined by scintillation counting after spotting onto strips of phosphocellulose filter paper, as described previously (Klann et al., 1993).

Electrophoresis and Western blot analyses. Tissue samples were homogenized, and protein concentrations were determined as described above. Equivalent amounts of protein for each sample were resolved by $10 \%$ SDS-PAGE, blotted electrophoretically to Immobilon membranes, and probed with a rabbit polyclonal antibody to either $\mathrm{PKC} \alpha, \beta, \gamma$, or $\zeta$ (Life Technologies, Gaithersburg, MD), phosphoT500-PKC $\beta$ II (a generous gift from Drs. A. C. Newton and J. Johnson, University of California, San Diego, CA), phosphoT634/641-PKC $\beta$ II (a generous gift from Dr. J. D. Sweatt, Baylor College of Medicine, Houston, TX), or phosphoS657-PKC $\alpha$ (Upstate Biotechnology, Lake Placid, NY) (1:500-1000 final dilution in each case). The blots then were exposed to a goat anti-rabbit IgGperoxidase-linked antibody, and developed using an enhanced chemiluminescence reagent. Densitometric analysis was conducted using NIH Image software.

Statistical analyses. Unless indicated otherwise, results from assays containing homogenate of dorsal CA1 tissue (experimental) were compared with those from assays containing homogenate of ventral CA1 tissue (control) derived from the same animals with Student's $t$ test for matched pairs. All tests were two-tailed, with the $\alpha$-level set to $\leq 0.05$.

\section{RESULTS}

\section{LTD in area CA1 of the adult hippocampus in vivo is accompanied by a decrease in autonomous and cofactor-dependent PKC activity}

To induce LTD of the commissural input to area CA1 of the hippocampus, we delivered three trains of paired-pulse stimulation (200 pairs of pulses with a $25 \mathrm{msec}$ interstimulus interval at $0.5 \mathrm{~Hz}$ per train) to the commissural fibers of anesthetized adult rats. Figure $1 A$ illustrates that paired-pulse stimulation produced a persistent depression of both the amplitude of the CA1 population spike (mean change from baseline $30 \mathrm{~min}$ after termination of the third train \pm SEM: $-4.0 \pm 0.3 \mathrm{mV}, n=12$; Fig. $1 \mathrm{Aa})$ and the initial slope of the CA1 population EPSP $(-0.7 \pm 0.1 \mathrm{mV} / \mathrm{msec}$, $n=6$; Fig. $1 \mathrm{Ab}$ ) evoked by test pulses before and after paired-pulse stimulation. We (Thiels et al., 1994) and others (Doyère et al., 1996) showed previously that LTD induced by paired-pulse stimulation in the adult hippocampus lasts for hours to days.

To examine whether LTD was accompanied by an alteration in $\mathrm{PKC}$ activity, we determined ${ }^{32} \mathrm{P}$ incorporation into $\mathrm{NG}_{(28-43)}$, an exogenous PKC substrate, in assays containing homogenates of tissue blocks excised from dorsal area CA1 near the recording site either 5, 35, or $65 \mathrm{~min}$ after termination of the third train of paired-pulse stimulation. ${ }^{32} \mathrm{P}$ incorporation into $\mathrm{NG}_{(28-43)}$ in assays containing dorsal CA1 homogenates was compared to that of assays containing homogenate of ventral area CA1 excised from the same animals at the same time (control homogenate). Ventral area CA1 is a cell field very similar to dorsal area CA1 with the important difference, however, that it is not innervated by the dorsal commissural pathway stimulated in these experiments (Laurberg, 1979; Ishizuka et al., 1990). Figure $1 B$ shows that PKC activity, as measured in terms of ${ }^{32} \mathrm{P}$ incorporation into $\mathrm{NG}_{(28-43)}$, was $25-40 \%$ lower for assays with dorsal CA1 homogenate (LTD) compared to assays with ventral CA1 homogenate (control) after the induction of LTD. This effect was observed with respect to autonomous PKC activity, i.e., enzyme activity measured in the absence of exogenously applied cofactors (Fig. $1 B a$ ), as well as cofactor-dependent PKC activity measured in the presence of the cofactors diacylglycerol, $\mathrm{Ca}^{2+}$, and phosphotidylserine (Fig. $1 \mathrm{Bb}$ ). The decrease in PKC activity was present within 5 min after the final LTD-inducing stimulation (for both autonomous and cofactor-dependent activity, control vs LTD, $n=6, p<0.05$ ) and lasted $>35$ min but $<65$ min after the final LTD-inducing stimulation $(35 \mathrm{~min}$ after the third train: both $n$ values $=12$, both $P$ values $<0.01 ; 65$ min after the third train: both $n$ values $=6$, both $P$ values $>0.1)$. Control experiments, also shown in Figure $1 B$, revealed that autonomous and cofactor-dependent PKC activity did not differ between dorsal and ventral area CA1 before LTDinducing stimulation, i.e., at the end of recording of baseline responses (both $n$ values $=6$, both $P$ values $>0.1$ ). Collectively, these findings suggest that LTD in the adult hippocampus in vivo is accompanied by a transient decrease in PKC activity below baseline levels.

We previously demonstrated that induction of LTD by pairedpulse stimulation requires activation of the NMDA receptor (Thiels et al., 1994). Delivery of paired-pulse stimulation in the presence of the specific NMDA receptor antagonist, D-APV, therefore enabled us to test the potential confound that the decrease in $\mathrm{PKC}$ activity resulted from patterned stimulation alone. Figure $2 A$ shows that three trains of paired-pulse stimulation failed to induce LTD when NMDA receptors near the recording site were blocked (change from baseline in the amplitude of the evoked population spike $5 \mathrm{~min}$ after the second train of pairs in the presence of D-APV: $0.5 \pm 0.2 \mathrm{mV}, n=5$, vs in the absence of D-APV: $-3.4 \pm$ $0.2 \mathrm{mV}, n=6 ; t$ test for independent groups, $p<0.01$ ). Figure $2 B$ shows that the decrease in both autonomous and cofactordependent PKC activity observed immediately after paired-pulse stimulation in the absence of NMDA receptor blockade (Fig. $1 B$ ) failed to occur when NMDA receptors were blocked (Fig. $2 \mathrm{Ba}$ : autonomous PKC activity, $n=5, p>0.1$; Fig. $2 B b$ : cofactordependent PKC activity, $n=5, p>0.1$ ). These findings demonstrate that repeated paired-pulse stimulation alone is not sufficient to cause a significant decrease in PKC activity. Taken together with the findings reported in Figure 1, our observations indicate that NMDA receptor activation sufficient to induce LTD is necessary for a decrease in PKC activity after paired-pulse stimulation.

\section{LTD in the adult hippocampus in vivo is not associated with a loss of either PKC $\alpha, \beta, \gamma$, or $\zeta$}

The observed decrease in cofactor-dependent PKC activity suggests that LTD in the adult hippocampus in vivo is associated with 


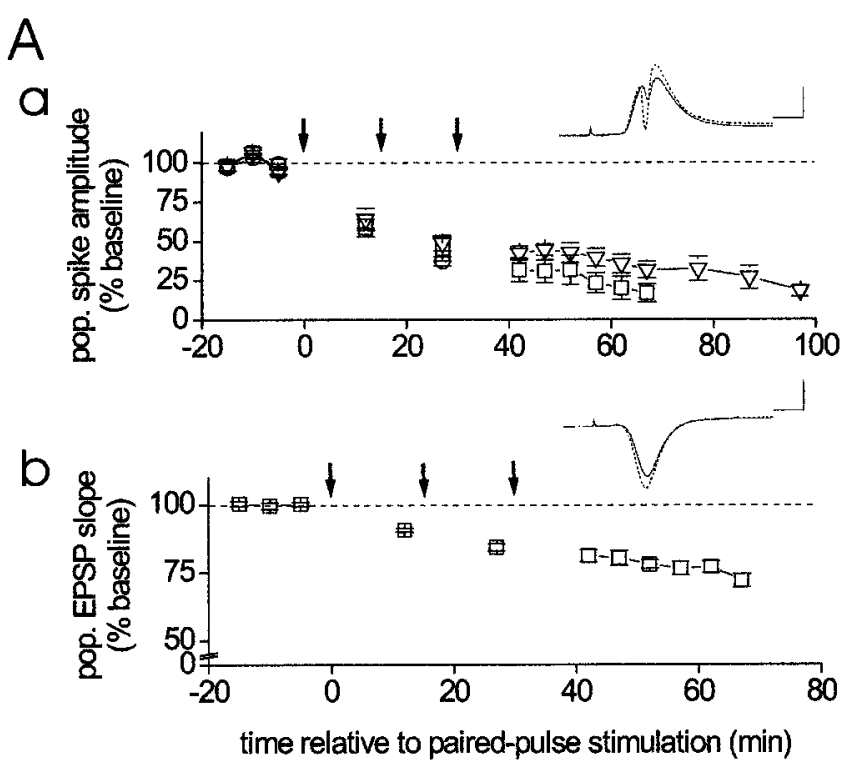

B

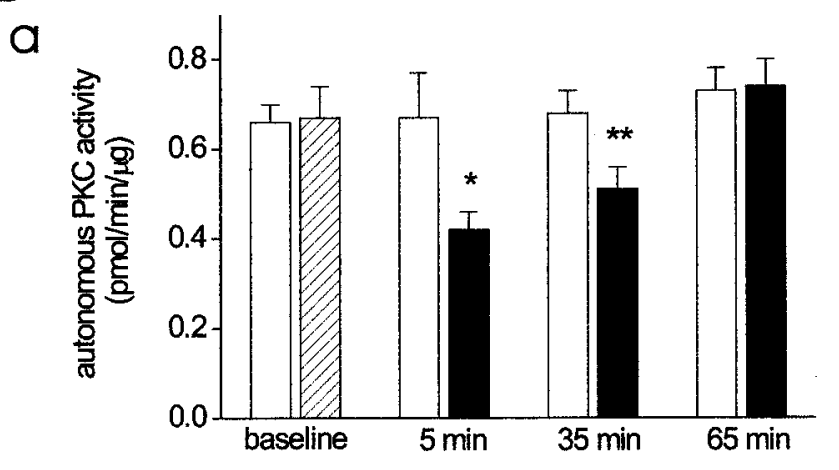

$b$

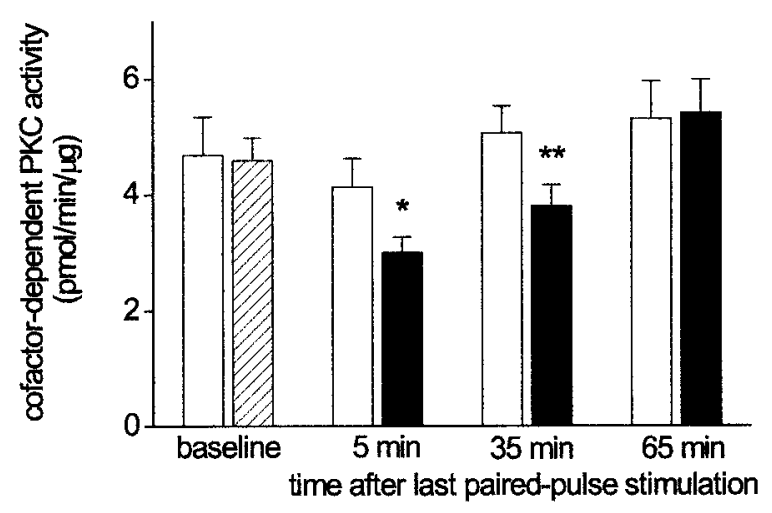

Figure 1. LTD in the adult hippocampus in vivo is associated with decreased autonomous and cofactor-dependent PKC activity. $A a$, Group data (mean $\pm \mathrm{SEM}$ ) of the amplitude of the CA1 pyramidal cell population spike evoked by stimulation of the commissural fibers before and after delivery of three trains of paired pulses (downward arrows) to these fibers. The data are expressed as a percentage of the average population spike amplitude before paired-pulse stimulation. Animals were killed either 5 min (circles; $n=6)$, 35 min (squares; $n=6)$, or 65 min (triangles; $n=6$ ) after termination of the third train of pairs. Inset, Average of 10 waveforms of population spikes recorded in the same animal $5 \mathrm{~min}$ before onset of the first train (stippled line) and $30 \mathrm{~min}$ after termination of the third train of pairs (solid line). Calibration: $4 \mathrm{mV}, 5 \mathrm{msec} . A b$, Similar group data of the initial slope of the CA1 pyramidal cell population EPSP recorded in st. radiatum before and after three trains of paired-pulse stimulation (downward arrows). All animals were killed 35 min after termination of the third train of pairs $(n=6)$. Inset, Averaged waveforms of population EPSPs recorded before and after paired-pulse stimulation, as described above (calibration as above). $\mathrm{Ba}$, Group data (mean $\pm \mathrm{SEM}$ ) of autonomous PKC activity in either ventral area CA1 homogenates (control; open bars) or dorsal area CA1 homogenates (baseline, striped bar; LTD, filled bars) for animals killed either 5 min after termination of baseline recording (base-
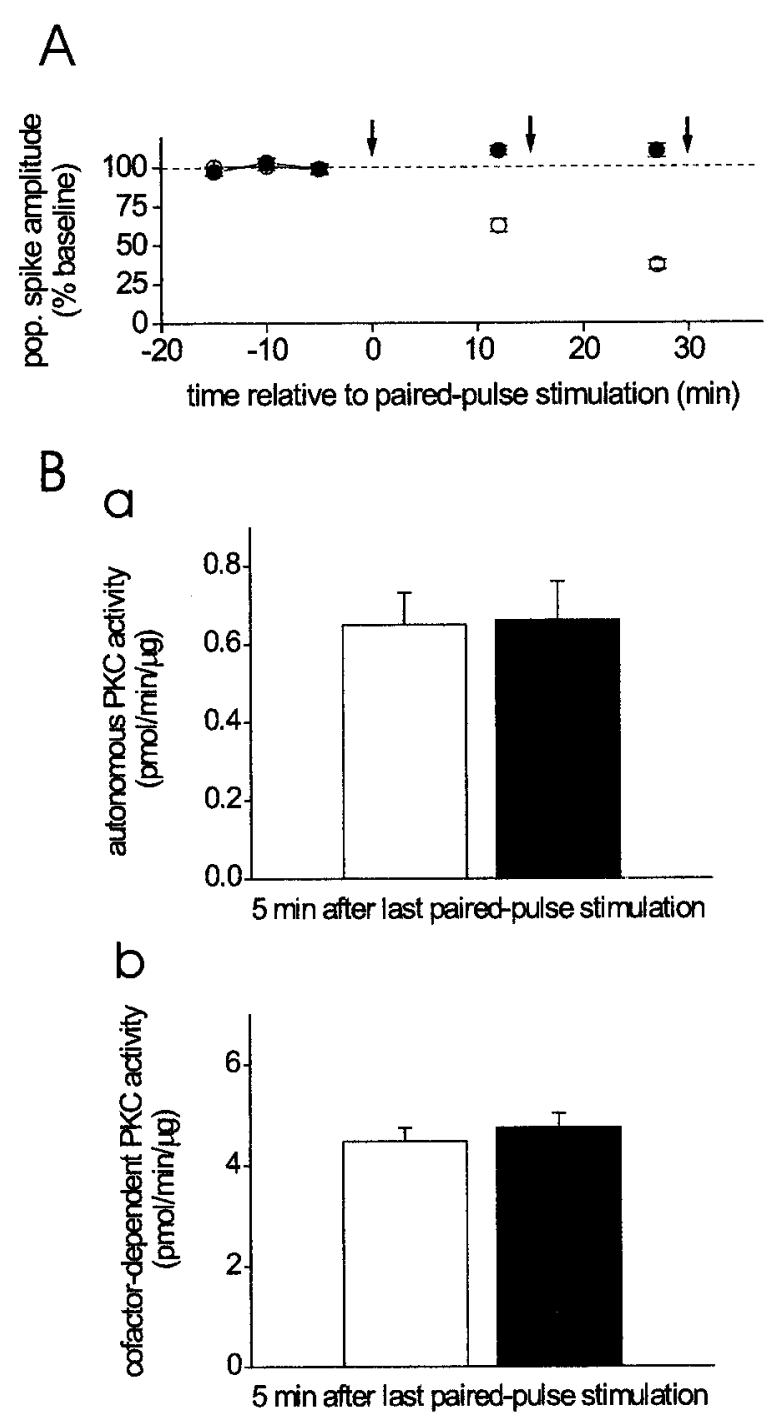

Figure 2. Blockade of the NMDA receptor prevents the induction of LTD as well as the associated decrease in autonomous and cofactor-dependent PKC activity. $A$, Group data (mean \pm SEM) of the amplitude of the evoked CA1 population spike recorded before and after three trains of paired-pulse stimulation (downward arrows) during continuous administration of the specific NMDA receptor antagonist D-APV $(100 \mu \mathrm{M}$ in the drug pipette; closed circles, $n=5)$. For purposes of comparison, the effect of paired-pulse stimulation in the absence of D-APV is depicted as well (open circles, $n=$ 6; data are taken from Fig. $1 A a)$. B, Group data (mean \pm SEM) of autonomous PKC activity $(a)$ and cofactor-dependent PKC activity $(b)$ in ventral (open bars) and dorsal (filled bars) area CA1 homogenates for animals who received paired-pulse stimulation in the presence of D-APV and were killed 5 min after termination of the third train of pairs $(n=5)$.

either a loss of mature enzyme or a posttranslational modification of the enzyme that renders it less able to become catalytically competent. To test the possibility of an LTD-associated reduction of enzyme level, we compared the level of either $\operatorname{PKC} \alpha, \beta, \gamma$, or $\zeta$ in dorsal area CA1 to that in ventral area CA1 both before pairedpulse stimulation (baseline) and $5 \mathrm{~min}$ after the third train of LTD-inducing stimulation using specific antibodies against the respective isozymes. As illustrated in Figure 3, there was no sig-

$\leftarrow$

line; $n=6)$ or either $5 \min (n=6), 35 \min (n=12)$, or $65 \min (n=6)$ after termination of the final LTD-inducing train. $B b$, Similar group data of cofactor-dependent PKC activity with the respective area CA1 homogenates. Asterisk indicates significant difference between control and LTD samples at the indicated time points (Student's $t$ test for matched samples; $* p<0.05, * * p<0.01)$. 

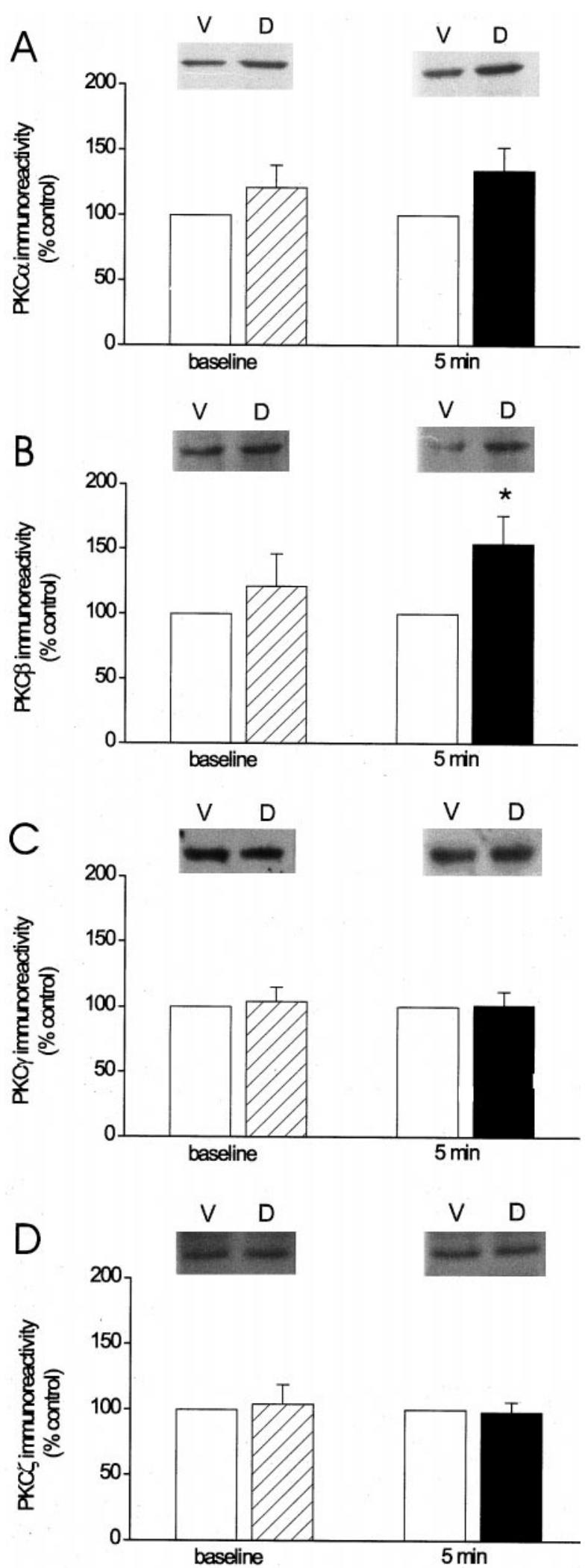

Figure 3. LTD in the adult hippocampus in vivo is not associated with a loss of either PKC $\alpha, \beta, \gamma$, or $\zeta$. A, Group data (mean \pm SEM) of PKC $\alpha$ immunoreactivity from dorsal area CA1 homogenate (baseline, striped bar; LTD, filled bar), expressed as a percentage of PKC $\alpha$ immunoreactivity from ventral area CA1 homogenate (control; open bars), either $5 \mathrm{~min}$ after baseline stimulation (baseline; $n=6$ ) or 5 min after termination of the final LTD-inducing stimulation ( $5 \mathrm{~min} ; n=6$ ). The amplitude of the evoked CA1 population spike recorded shortly before the third LTD-inducing stimulation was, on average, $52 \pm 9 \%$ of baseline level. Representative Western blots of PKC $\alpha$ for ventral $(V)$ and dorsal $(D)$ area CA1 homog- nificant difference in isozyme immunoreactivity between assays containing homogenate of dorsal versus ventral area CA1 during baseline or after the induction of LTD with respect to PKC $\alpha$ (Fig. $3 a$; both $n$ values $=6 ; p>0.1$ and $p>0.05$ for baseline and $5 \mathrm{~min}$ after LTD induction, respectively), PKC $\gamma$ (Fig. $3 c$; both $n$ values $=$ 8 ; both $P$ values $>0.1$ ), or PKC $\zeta$ (Fig. $3 d$; both $n$ values $=8$, both $P$ values $>0.1)$. Because of previous observations of a delayed effect on the level of persistently active $\mathrm{PKC} \zeta, \mathrm{PKM} \zeta$, during LTD in immature hippocampus in vitro (Hrabetova and Sacktor, 1996), we also compared PKC $\zeta$ immunoreactivity between assays with homogenate from dorsal versus ventral area CA1 excised $35 \mathrm{~min}$ after LTD induction. However, similar to the results observed immediately after LTD induction, there was no significant difference in PKC $\zeta$ immunoreactivity for tissue collected at the later time point (immunoreactivity for dorsal area CA1, expressed as a percentage of control, $100 \pm 4 \%, n=6, p>0.1)$. PKC $\beta$ immunoreactivity did not differ between assays with dorsal versus ventral area CA1 homogenate during baseline (Fig. $3 b ; n=6 ; p>0.1$ ) but, surprisingly, was increased significantly in assays containing dorsal CA1 homogenate compared to those containing ventral area CA1 homogenate after the induction of LTD (Fig. $3 b ; n=6 ; p<0.05$ ). Control experiments with APV administration during paired-pulse stimulation, similar to those described above, revealed that the observed increase of $\mathrm{PKC} \beta$ did not depend on prior induction of LTD but developed after patterned stimulation in the absence of LTD induction (immunoreactivity for dorsal area CA1, expressed as a percentage of control, $130 \pm 12 \%$; $n=4 ; p<0.05$ ).

To test further the possibility that the observed decrease in PKC activity resulted from loss of enzyme, we compared the level of the catalytic fragment of either $\operatorname{PKC} \alpha$ or $\beta$, the only two isozymes whose catalytic fragment was clearly recognizable by the antibody, between dorsal and ventral area CA1 before and after LTD induction. We found no systematic differences in immunoreactivity between assays with dorsal and ventral area CA1 homogenate either before or after LTD induction (immunoreactivity in dorsal area $\mathrm{CA} 1$, expressed as a percentage of control, for $\mathrm{PKC} \alpha$ : baseline $=$ $85 \pm 8 \%, n=6, p>0.1 ; 5$ min after final stimulation train $=97 \pm$ $13 \%, n=6, p>0.1$; for PKC $\beta$ : baseline $=87 \pm 6 \%, n=6, p>$ $0.1 ; 5$ min after final stimulation train $=93 \pm 9 \%, n=6, p>0.1$ ). Collectively, these findings do not support the idea that the decrease in cofactor-dependent (and autonomous) PKC activity observed in association with LTD in the adult hippocampus in vivo results from decreased synthesis and/or increased proteolysis of one or several PKC isozymes.

\section{LTD in the adult hippocampus in vivo is associated with a protein phosphatase-mediated reduction of phosphorylation at C-terminal autophosphorylation sites of PKC}

An alternative explanation for the decrease in both types of PKC activity is dephosphorylation of the catalytic domain of PKC by protein phosphatases. To address this possibility, we focused on the transphosphorylation site Thr-500 on PKC $\beta$ II (Thr-497 on PKC $\alpha$ ) and the autophosphorylation sites Thr-634/Thr-641 on PKC $\alpha / \beta \mathrm{II}$ and Ser-657 on PKC $\alpha$ (Ser-660 on PKC $\beta$ II). The transphosphorylation site is located on the activation loop of the enzyme, and its

enate for baseline and 5 min after LTD-inducing stimulation. $B$, Similar group data of PKC $\beta$ immunoreactivity and representative Western blots (baseline, $n=6 ; 5 \min , n=6$ ). The amplitude of the evoked population spike recorded shortly before the third LTD-inducing stimulation was, on average, $52 \pm 9 \%$ of baseline level. Asterisk indicates significant difference between control and LTD samples at the indicated time point (Student's $t$ test for matched samples; $\left.{ }^{*} p<0.05\right)$. $C$, Similar group data of $\mathrm{PKC} \gamma$ immunoreactivity and representative Western blots (baseline, $n=8 ; 5 \mathrm{~min}$, $n=8)$. The amplitude of the evoked population spike recorded shortly before the third LTD-inducing stimulation was, on average, $42 \pm 5 \%$ of baseline level. $D$, Similar group data of PKC $\zeta$ immunoreactivity and representative Western blots (baseline, $n=8 ; 5 \mathrm{~min}, n=8$ ). The amplitude of the evoked population spike recorded shortly before the third LTDinducing stimulation was, on average, $42 \pm 5 \%$ of baseline level. 

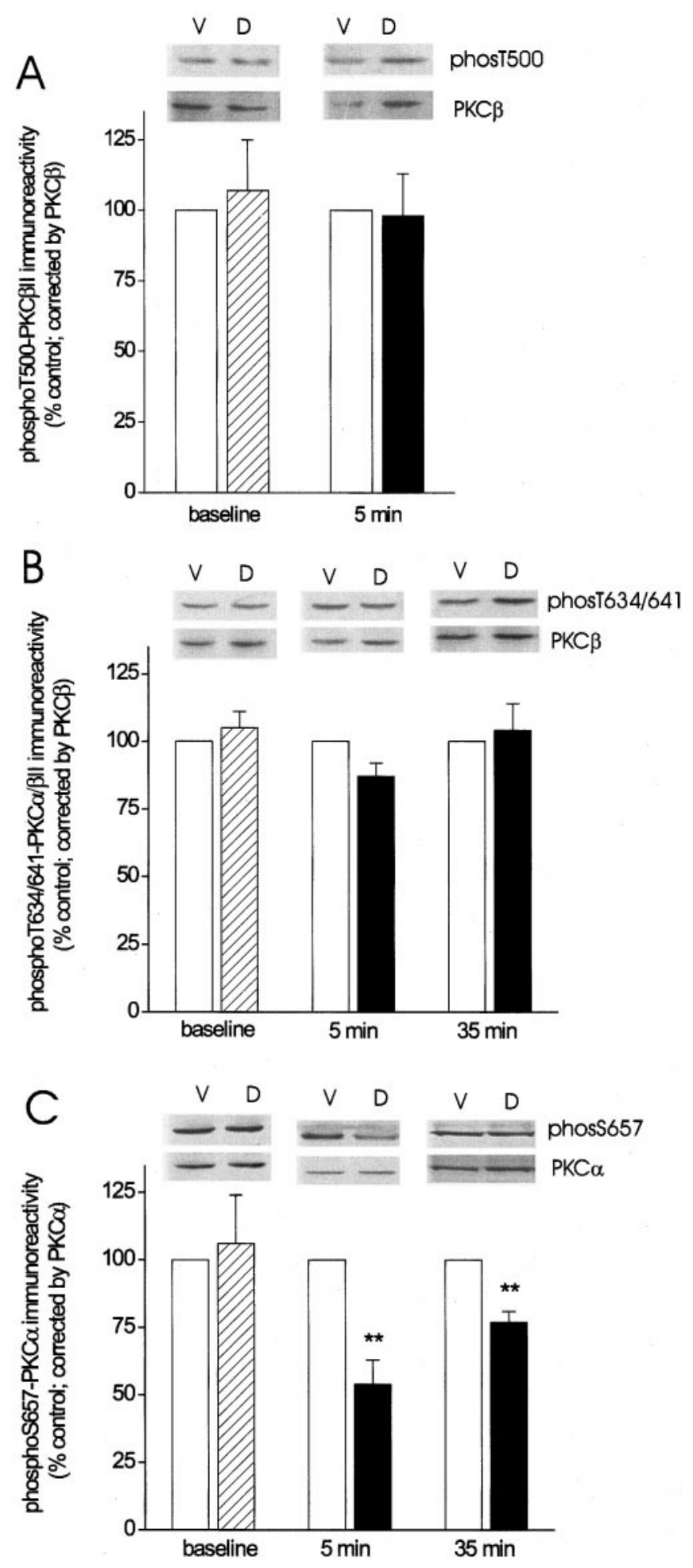

Figure 4. LTD in the adult hippocampus in vivo is accompanied by a decrease in phosphorylation at Ser-657 on the C terminus of PKC $\alpha$. A, Group data (mean \pm SEM) of phosphoT500-PKC $\beta$ II immunoreactivity from dorsal area CA1 homogenate (baseline, striped bar; LTD, filled bar), expressed as a percentage of phosphoT500-PKC $\beta$ II immunoreactivity from ventral area CA1 homogenate (control; open bars) and corrected by total PKC $\beta$, either 5 min after baseline stimulation (baseline; $n=6$ ) or 5 min after termination of the final LTD-inducing stimulation ( $5 \mathrm{~min} ; n=6$ ). The amplitude of the evoked CA1 population spike recorded shortly before the third LTDinducing stimulation was, on average, $52 \pm 9 \%$ of baseline level. Representative Western blots of phosphoT500-PKC $\beta$ II and PKC $\beta$ for ventral $(V)$ and dorsal $(D)$ area CA1 homogenate for baseline and $5 \mathrm{~min}$ after LTD-inducing stimulation. $B$, Similar group data of phosphoT634/T641-PKC $\alpha / \beta$ II immunoreactivity and representative Western blots, except that data for $35 \mathrm{~min}$ after termination of the final LTD-inducing stimulation are depicted as phosphorylation is required for maturation to the cofactorsensitive, catalytically competent state (Orr and Newton, 1994; Bornancin and Parker, 1997). Both autophosphorylation sites are located on the $\mathrm{C}$ terminus, and their phosphorylation plays a critical role in the enzymatic function of $\mathrm{PKC}$, although their relative importance to PKC activity is controversial (Dutil et al., 1994; Zhang et al., 1994; Keranen et al., 1995; Bornancin and Parker, 1996, 1997; Gysin and Imber, 1996; Sweatt et al., 1998; Edwards et al., 1999). Using antibodies that selectively recognize PKC $\beta$ II when phosphorylated at Thr-500, PKC $\alpha$ and $\beta$ II when phosphorylated at Thr-634/Thr-641, and PKC $\alpha$ when phosphorylated at Ser-657, we compared immunoreactivity in assays with dorsal versus ventral area CA1 homogenate before paired-pulse stimulation and at various times after termination of the final LTD-inducing stimulation. Figure 4 illustrates that there was no systematic difference between dorsal and ventral area CA1 before LTD induction with respect to phosphorylation of Thr-500 (Fig. $4 A ; n=6 ; p>0.1$ ), Thr-634/Thr-641 on PKC $\alpha / \beta$ II (Fig. $4 B ; n=$ $4 ; p>0.1$ ), or Ser-657 on PKC $\alpha$ (Fig. $4 C ; n=6 ; p>0.1$ ). Five minutes after the induction of LTD, the phosphorylation level at the transphosphorylation site was unchanged, relative to control levels (Fig. $4 A ; n=6 ; p>0.1$ ), whereas at both autophosphorylation sites it was reduced, as indicated by relatively lower immunoreactivity in assays with dorsal compared to ventral area CA1 homogenate. With respect to Thr-634/Thr-641 on $\mathrm{PKC} \alpha / \beta \mathrm{II}$, the reduction in phosphorylation level, albeit a clear trend immediately after LTD induction, failed to reach statistical significance either 5 or $35 \mathrm{~min}$ after LTD induction (Fig, $4 B ; 5 \mathrm{~min}$ after the final LTD-inducing stimulation: $n=6,0.1>p>0.05$; 35 min after the third stimulation train: $n=7, p>0.1$ ). However, with respect to Ser-657 on $\mathrm{PKC} \alpha$, the reduction in phosphorylation level was pronounced and lasted at least $35 \mathrm{~min}$ after the final LTD-inducing stimulation (Fig. $4 C ; 5$ min after the third stimulation train: $n=6$, $p<0.01 ; 35$ min after the third train: $n=8, p<0.01)$. Control experiments with APV administration during paired-pulse stimulation, similar to those described above, revealed that the dephosphorylation of the Ser-657 autophosphorylation site required prior induction of NMDA receptor-dependent LTD, because the difference in immunoreactivity in assays with dorsal versus ventral area CA1 homogenates was abolished in experiments with the NMDA receptor antagonist (phosphoSer-657 immunoreactivity for dorsal area CA1, expressed as a percentage of control and corrected by total $\mathrm{PKC} \alpha, 99 \pm 5 \%, n=4, p>0.1)$. Taken together, these findings suggest that LTD in the adult hippocampus in vivo is accompanied by dephosphorylation of the catalytic domain of $\mathrm{PKC}$, with the specific dephosphorylation target identified here being the Ser-657 autophosphorylation site on the $\mathrm{C}$ terminus of PKC $\alpha$.

Previous studies showed that PKC activity (Dutil et al., 1994; Bornancin and Parker, 1996, 1997; Lee et al., 1996; Sweatt et al., 1998) as well as phosphorylation at Ser-657 on PKC $\alpha$ (Bornancin

well (baseline, $n=4 ; 5 \mathrm{~min}, n=6 ; 35 \mathrm{~min}, n=7$ ). The amplitude of the evoked population spike recorded from animals in the 5 min group shortly before the third LTD-inducing stimulation was, on average, $47 \pm 4 \%$ of baseline level; the amplitude of the evoked population spike recorded from animals in the $35 \mathrm{~min}$ group $30 \mathrm{~min}$ after the final LTD-inducing stimulation was, on average, $16 \pm 10 \%$ of baseline level $(n=3)$, and the slope of the evoked population EPSP recorded from animals in the $35 \mathrm{~min}$ group at that time point was, on average, $79 \pm 2 \%$ of baseline level $(n=4)$. $C$, Similar group data of phosphoS657-PKC $\alpha$ immunoreactivity and representative Western blots (baseline, $n=6 ; 5 \mathrm{~min}, n=6 ; 35 \mathrm{~min}, n=8$ ). The amplitude of the evoked population spike recorded from animals in the 5 min group shortly before the third LTD-inducing stimulation was, on average, $52 \pm 9 \%$ of baseline level; the amplitude of the evoked population spike recorded from animals in the 35 min group $30 \mathrm{~min}$ after the final LTD-inducing stimulation was, on average, $16 \pm 10 \%$ of baseline level $(n=$ 3 ), and the slope of the evoked population EPSP recorded from animals in the 35 min group at that time point was, on average, $74 \pm 2 \%$ of baseline level $(n=5)$. Asterisk indicates significant difference between control and LTD samples at the indicated time point (Student's $t$ test for matched samples; $* * p<0.01)$. 
A

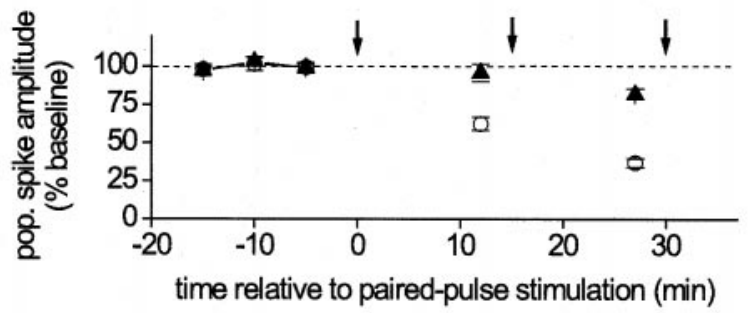

B

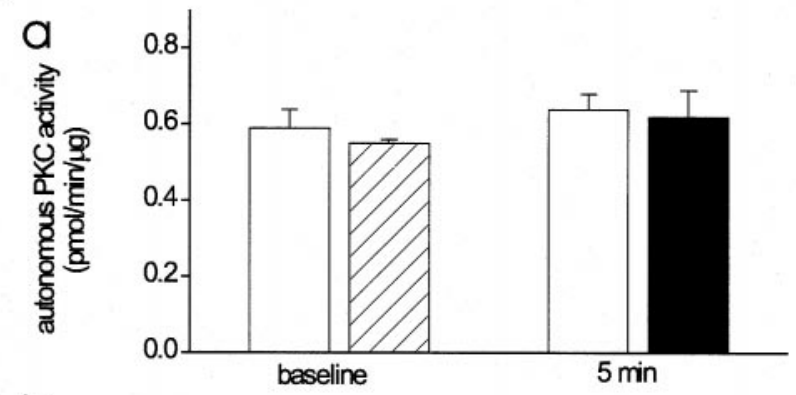

b
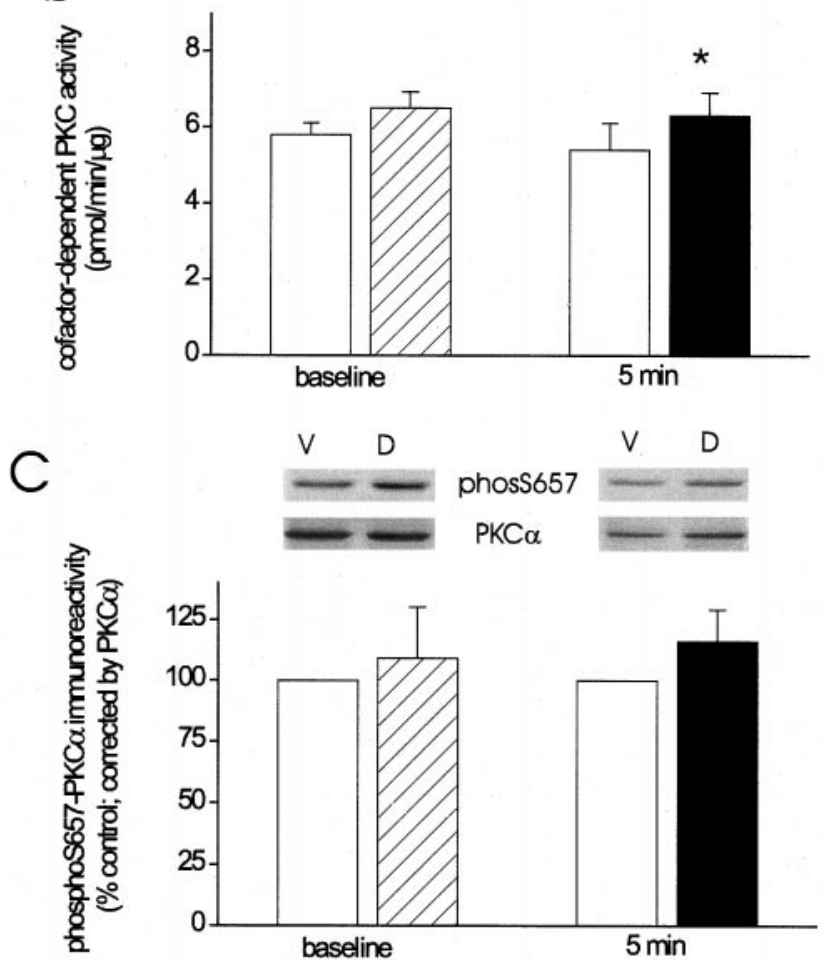

Figure 5. The LTD-associated decrease in PKC activity and dephosphorylation of the Ser-657 autophosphorylation site on $\mathrm{PKC} \alpha$ are blocked by okadaic acid. $A$, Group data (mean \pm SEM) of the amplitude of the evoked CA1 population spike recorded before and after three trains of paired-pulse stimulation (downward arrows) during continuous administration of okadaic acid (5-10 $\mu \mathrm{M}$ in the drug pipette; closed triangles, $n=7)$, a potent inhibitor of PP1 and PP2A. For purposes of comparison, the effect of paired-pulse stimulation in the absence of okadaic acid is depicted as well (open circles, $n=6$; data are taken from Fig. $1 A a$ ). B, Group data (mean \pm SEM) of autonomous PKC activity $(a)$ and cofactor-dependent PKC activity $(b)$ in ventral (open bars) and dorsal (striped or filled bars) area CA1 homogenates for animals who received test pulse and paired-pulse stimulation in the presence of okadaic acid and were killed either 5 min after termination of baseline recording (baseline; $n=4$ ) or $5 \mathrm{~min}$ after termination of the third train of pairs $(n=7)$. Asterisk indicates significant difference at the indicated time point between control samples and samples that received paired-pulse stimulation in the presence of OA (Student's $t$ test for matched samples; $\left.{ }^{*} p<0.05\right)$. $C$, Group data (mean $\pm \mathrm{SEM}$ ) of phosphoS657-PKC $\alpha$ immunoreactivity from dorsal area CA1 homogenate and Parker, 1997) are regulated negatively by PP1 and/or PP2A, protein phosphatases whose activity is increased after the induction of LTD (Thiels et al., 1998). We therefore tested whether the LTD-associated decrease in autonomous and cofactor-dependent PKC activity and dephosphorylation of Ser-657 on PKC $\alpha$ could be blocked by the serine/threonine protein phosphatase inhibitor, okadaic acid. To that end, we delivered three trains of paired-pulse stimulation in the presence of okadaic acid (5-10 $\mu \mathrm{M}$ in the drug pipette) and then analyzed the tissue for both ${ }^{32} \mathrm{P}$ incorporation into $\mathrm{NG}_{(28-43)}$ and immunoreactivity to the phosphospecific antibody. Figure $5 A$ illustrates that LTD was attenuated markedly when paired-pulse stimulation was delivered in the presence of the phosphatase inhibitor (change from baseline in the amplitude of the evoked population spike 5 min after the second train of pairs in the presence of okadaic acid: $-0.8 \pm 0.3 \mathrm{mV}, n=7$, vs in the absence of okadaic acid: $-3.4 \pm 0.2 \mathrm{mV}, n=6$; $t$ test for independent groups, $p<0.01)$. The effect of okadaic acid on LTDassociated changes in PKC activity are depicted in Figure 5B. Part $a$ shows that there was no difference in autonomous PKC activity between assays with dorsal versus ventral CA1 homogenate either before or after paired-pulse stimulation in the presence of okadaic acid (baseline, $n=4, p>0.1 ; 5$ min after the final stimulation train, $n=7, p>0.1$ ). Part $b$ shows that there was a trend for cofactordependent PKC activity to be higher in assays with dorsal CA1 homogenate compared to those with ventral CA1 homogenate both before and after paired-pulse stimulation in the presence of okadaic acid (baseline, $n=4,0.1>p>0.05 ; 5$ min after the final stimulation train, $n=7, p<0.05)$. Thus, the LTD-associated decrease in autonomous PKC activity (Fig. $1 \mathrm{Ba}$ ) and that in cofactor-dependent PKC activity (Fig. $1 B b$ ) both were abolished when okadaic acid-sensitive protein phosphatases were inhibited. The higher level of cofactor-dependent PKC activity in homogenate of dorsal area CA1, the site of okadaic acid administration, is likely to reflect higher levels of catalytically competent PKC in the presence of the phosphatase inhibitor. Consistent with this suggestion, probing the same homogenates with the anti-PKC $\alpha$ antibody revealed slightly but systematically stronger immunoreactivity in assays with dorsal versus ventral area CA1 homogenate (dorsal, as a percentage of ventral; baseline: $137 \pm 14 \%, n=5, p<0.05 ; 5 \mathrm{~min}$ after the third stimulation train: $134 \pm 6 \%, n=7, p<0.01)$. The effect of okadaic acid on phosphorylation at Ser-657 on PKC $\alpha$ is depicted in Figure $5 C$. In the presence of okadaic acid, phosphorylation at this site was indistinguishable between assays with dorsal versus ventral area CA1 homogenate both before and after pairedpulse stimulation (baseline, $n=5, p>0.1 ; 5$ min after the third stimulation train, $n=7, p>0.1$ ). Thus, similar to the pattern observed with respect to PKC activity, the LTD-associated decrease in phosphorylation at Ser-657 on PKC $\alpha$ (Fig. $4 C$ ) was abolished completely when okadaic acid-sensitive protein phosphatases were inhibited. Collectively, these findings indicate that increased activity of okadaic acid-sensitive protein phosphatases following the induction of LTD was responsible for both the decrease in phosphorylation at Ser-657 on PKC $\alpha$ and the decrease in PKC activity observed after LTD induction in adult hippocampus in vivo. A summary of all the findings is presented in Table 1.

\section{DISCUSSION}

We examined the regulation of PKC activity during NMDA receptor-dependent LTD in area CA1 of the adult hippocampus in vivo. We found that autonomous PKC activity is reduced below basal levels for a period of 30-60 min after the final LTD-inducing

$\leftarrow$

(baseline, striped bar; LTD, filled bar), expressed as a percentage of phosphoS657-PKC $\alpha$ immunoreactivity from ventral area CA1 homogenate (control; open bars) and corrected by total $\mathrm{PKC} \alpha$, for animals who received test pulses and paired-pulse stimulation in the presence of okadaic acid and were killed either $5 \mathrm{~min}$ after baseline stimulation (baseline; $n=5$ ) or 5 min after termination of the third train of pairs $(5 \min ; n=7)$. Representative Western blots of phosphoS657-PKC $\alpha$ and PKC $\alpha$ for ventral $(V)$ and dorsal $(D)$ area CA1 homogenate for baseline and $5 \mathrm{~min}$ after LTD-inducing stimulation. 
Table 1. Summary of the electrophysiological and biochemical changes produced by LTD-inducing stimulation

\begin{tabular}{|c|c|c|c|c|c|c|}
\hline & Baseline (\%) & $5 \min (\%)$ & $35 \min (\%)$ & $65 \min (\%)$ & $\mathrm{APV}, 5 \min (\%)$ & $\mathrm{OA}, 5 \min (\%)$ \\
\hline Population spike amplitude & 0 & $-55 \pm 4(n=18)$ & $-83 \pm 5(n=9)$ & $-82 \pm 3(n=6)$ & $12 \pm 3(n=9)$ & $-20 \pm 4(n=7)$ \\
\hline Population EPSP slope & 0 & - & $-26 \pm 2(n=9)$ & - & - & - \\
\hline Autonomous PKC activity & $2 \pm 12(n=6)$ & $-35 \pm 6(n=6)^{*}$ & $-26 \pm 4(n=12)^{* *}$ & $3 \pm 12(n=6)$ & $4 \pm 11(n=5)$ & $-1 \pm 13(n=7)$ \\
\hline \multicolumn{7}{|l|}{ Cofactor-dependent PKC } \\
\hline activity & $6 \pm 13(n=6)$ & $-25 \pm 8(n=6)^{*}$ & $-24 \pm 6(n=12)^{* *}$ & $4 \pm 8(n=6)$ & $7 \pm 8(n=5)$ & $26 \pm 10(n=7)^{*}$ \\
\hline $\mathrm{PKC} \alpha$ immunoreactivity & $21 \pm 17(n=6)$ & $34 \pm 18(n=6)$ & - & - & $8 \pm 5(n=4)$ & $34 \pm 6(n=7)^{*}$ \\
\hline $\mathrm{PKC} \beta$ immunoreactivity & $21 \pm 25(n=6)$ & $54 \pm 22(n=6)^{*}$ & - & - & $30 \pm 12(n=4)^{*}$ & - \\
\hline PKC $\gamma$ immunoreactivity & $4 \pm 11(n=8)$ & $1 \pm 11(n=8)$ & - & - & - & - \\
\hline PKC $\zeta$ immunoreactivity & $4 \pm 15(n=8)$ & $-2 \pm 8(n=8)$ & $0 \pm 4(n=6)$ & - & - & - \\
\hline activity & $7 \pm 18(n=6)$ & $-2 \pm 15(n=6)$ & - & - & - & - \\
\hline \multicolumn{7}{|l|}{ phosT634/T641-PKC $\alpha / \beta \mathrm{II}$} \\
\hline immunoreactivity & $5 \pm 6(n=4)$ & $-13 \pm 5(n=6)$ & $4 \pm 10(n=7)$ & - & - & - \\
\hline activity & $6 \pm 18(n=6)$ & $-46 \pm 9(n=5)^{* *}$ & $-23 \pm 4(n=8) * *$ & - & $-1 \pm 5(n=4)$ & $16 \pm 13(n=7)$ \\
\hline
\end{tabular}

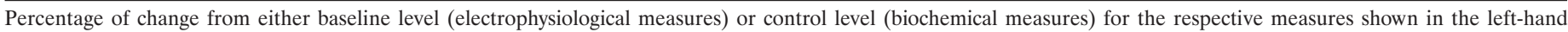

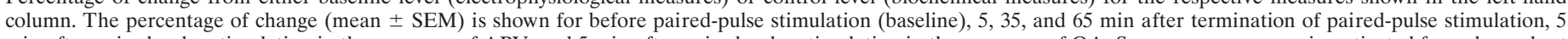

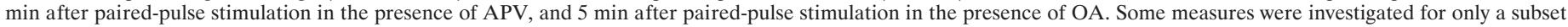
of the time points and/or drug conditions. Asterisks denote statistically significant differences from control level (see Results; ${ }^{*} P<0.05, * * P<0.01$ ).

stimulation. These findings are consistent with a previous report of reduced PKC activity during NMDA receptor-dependent LTD in area CA1 of hippocampal slices from young animals (Hrabetova and Sacktor, 1996). They also are consistent with a previous report that NMDA receptor-dependent LTD is not affected by a PKC inhibitor (Oliet et al., 1997; Nicoll et al., 1998). Interestingly, in that latter study it was found that metabotropic glutamate and $\mathrm{GABA}_{\mathrm{A}}$ receptor-dependent LTD in area CA1 of hippocampal slices from young animals is blocked during inhibition of PKC activity (Oliet et al., 1997), which suggests that this form of LTD involves an increase in PKC activity. Although the form of LTD studied here is $\mathrm{GABA}_{\mathrm{A}}$ receptor-dependent as well (Thiels et al., 1994), the biochemical cascade that underlies $\mathrm{GABA}_{\mathrm{A}}$ receptor-dependent LTD in the adult hippocampus in vivo does not appear to resemble that of $\mathrm{GABA}_{\mathrm{A}}$ receptor-dependent LTD induced by prolonged lowfrequency stimulation in hippocampal slices of preweaning-aged animals.

In addition to the change in autonomous PKC activity, we observed an LTD-associated decrease in cofactor-dependent PKC activity whose time course paralleled that of autonomous PKC activity. The change in cofactor-dependent activity suggested that during LTD either PKC synthesis is decreased, its degradation is increased, or its catalytic competence is corrupted. To evaluate the first two possibilities, we determined whether LTD was associated with a decrease in the level of $\mathrm{PKC} \alpha, \beta, \gamma$, or $\zeta$. We found no evidence for reduced levels of any of these isozymes at a time after LTD induction at which PKC activity levels were decreased significantly. Thus, the LTD-associated change in PKC activity cannot readily be explained in terms of downregulation or accelerated degradation of the kinase. This conclusion is supported further by our observed lack of an LTD effect on the level of the catalytic fragments of $\mathrm{PKC} \alpha$ or $\beta$. These results are not consistent with findings of a significant, proteolysis-mediated decrease in $\mathrm{PKC} \gamma$ and PKM $\zeta$ after the induction of LTD in area CA1 of hippocampal slices from preweaning-aged rats (Hrabetova and Sacktor, 1996). This inconsistency in outcome raises the interesting possibility of a developmental change in the regulation of PKC during synaptic plasticity. Alternatively, the type of LTD studied here, which was induced with paired-pulse stimulation, may differ from the type studied in the slice preparation, which was induced with prolonged low-frequency stimulation. Whereas blockade of $\mathrm{GABA}_{\mathrm{A}}$ receptors prevents LTD induced by paired-pulse stimulation (Thiels et al., 1994), it does not affect or facilitate LTD induced by lowfrequency stimulation (Wagner and Alger, 1995).

To evaluate the possibility that the observed reduction in PKC activity stems from a posttranslational modification that renders the enzyme less able to become activated, we determined whether LTD was associated with dephosphorylation of a transphosphorylation site implicated in the maturation of PKC to catalytic competence (Cazaubon et al., 1994; Orr and Newton, 1994) and/or two autophosphorylation sites implicated in the catalytic activity of PKC (Dutil et al., 1994; Zhang et al., 1994; Keranen et al., 1995; Gysin and Imber, 1996; Bornancin and Parker, 1997; Sweatt et al., 1998; Edwards et al., 1999). Although phosphorylation of Thr-500 on PKC $\beta$ II (Thr-497 on PKC $\alpha$ ) was found to not be essential for enzymatic function provided that the enzyme had progressed to the state of phosphorylation at Thr-641 (Keranen et al., 1995), we considered the possibility that PKC newly synthesized after LTDinducing stimulation was dephosphorylated by PP1 and/or PP2A (Dutil et al., 1994; Keranen et al., 1995) and thereby rendered inactivatable. We found that phosphorylation at Thr-500 on PKC $\beta$ II was not affected by LTD-inducing stimulation, which suggests that maturation of PKC proceeds normally during LTD in the adult hippocampus in vivo.

Phosphorylation of Thr-634/Thr-641 on PKC $\alpha / \beta$ II has been shown to be increased after the induction of LTP in area CA1 (Sweatt et al., 1998), coincident with elevated autonomous PKC activity after LTP induction (Lovinger et al., 1985; Klann et al., 1991, 1993; Gianotti et al., 1992; Sacktor et al., 1993; Osten et al., 1996). Recent work provides evidence for a direct link between phosphorylation of this site and catalytic activity of the enzyme (Sweatt et al., 1998; Edwards et al., 1999). In the present study we found that, in contrast to LTP, during LTD the level of phosphorylation of Thr-634/Thr-641 on $\mathrm{PKC} \alpha / \beta \mathrm{II}$ was not significantly changed from control or basal levels. Nevertheless, we observed a marked reduction of autonomous PKC activity that could not readily be attributed to a loss in the amount of enzyme. Thus, in hippocampal cells in vivo, phosphorylation at Thr-634/Thr-641 on $\mathrm{PKC} \alpha / \beta \mathrm{II}$ in the absence of phosphorylation at Ser-657 on PKC $\alpha$ (Ser-660 on PKC $\beta \mathrm{II}$ ) does not appear to be sufficient for catalytic activity of the enzyme.

Phosphorylation of Ser-657 on PKC $\alpha$ (Ser-660 on PKC $\beta$ II) has been shown to play a role in the catalytic activity (Gysin and Imber, 1996; Bornancin and Parker, 1997), the affinity to cofactors and substrate (Edwards and Newton, 1997), the subcellular localization (Keranen et al., 1995; Gysin and Imber, 1996; Feng and Hannun, 1998; Edwards et al., 1999), and the stabilization and phosphatase resistance (Gysin and Imber, 1996; Bornancin and Parker, 1997; Edwards and Newton, 1997) of PKC. Consistent with observations that this site is subject to dephosphorylation by PP1 and PP2A 
(Dutil et al., 1994; Bornancin and Parker, 1997) and our previous findings of increased PP1 and PP2A activity during LTD (Thiels et al., 1998), we found LTD to be associated with a decrease in phosphorylation at Ser-657 on PKC $\alpha$. Furthermore, we found that the LTD-associated dephosphorylation of this autophosphorylation site as well as the LTD-associated decreases in autonomous and cofactor-dependent PKC activity were blocked when pairedpulse stimulation was delivered during inhibition of okadaic acidsensitive protein phosphatases. In light of evidence that phosphorylation at the Ser-657 (Ser-660) autophosphorylation site regulates PKC activity (Gysin and Imber, 1996; Bornancin and Parker, 1997) as well as substrate and cofactor affinity (Edwards and Newton, 1997), the most parsimonious explanation of the decrease in both autonomous and cofactor-dependent PKC activity during LTD is that okadaic acid-sensitive phosphatases activated upon LTDinducing stimulation, such as PP1 and PP2A, dephosphorylate the autophosphorylation site on the $\mathrm{C}$ terminus of PKC and thereby render the enzyme less active and less capable of becoming activated by cofactors.

An interesting question that arises from our findings concerns the identity of the proteins that experience reduced PKC-mediated phosphorylation during LTD. Recent evidence shows that NMDAinduced LTD in hippocampus in vitro is not associated with a decrease in phosphorylation at the major PKC phosphorylation site on the AMPA receptor (Roche et al., 1996; Lee et al., 1998), although it remains to be determined whether phosphorylation at this PKC site also is unaffected during the type of LTD studied here. Another possible target is the ERK signaling cascade, because recent findings suggest that PKC regulates this kinase cascade, including ERK-mediated phosphorylation of the transcription factor cAMP responsive element-binding protein, during LTP in hippocampus in vitro (Roberson et al., 1999). Finally, based on our preparation, we cannot exclude the possibility that the observed changes in PKC activity occur presynaptically and affect presynaptic targets, as is suggested by the recent report of reduced phosphorylation of growth-associated protein-43 during LTD in juvenile hippocampus in vitro (Ramakers et al., 1999).

In conclusion, we have demonstrated that LTD in adult hippocampus in vivo is associated with a transient decrease in PKC activity that is mediated by okadaic acid-sensitive protein phosphatases. In light of our previous findings of increased PP1 and PP2A activity during the same form of LTD studied here, we hypothesize that the protein phosphatases responsible for the alteration in PKC activity are PP1 and/or PP2A. The reduction in PKC activity does not appear to result from reduced synthesis or increased proteolytic degradation of the kinase during LTD. Rather, it likely results, at least in part, from dephosphorylation of catalytically relevant autophosphorylation sites on the $\mathrm{C}$ terminus of PKC. Reduced PKC activity during LTD is likely to contribute to a net dephosphorylation effect that is believed to underlie the expression of early-phase LTD (Bear and Malenka, 1994; Lisman, 1994; Malenka, 1994; Schulman, 1994).

\section{REFERENCES}

Anderson NG, Maller JL, Tonks NK, Sturgill TW (1990) Requirement for integration of signals from two distinct phosphorylation pathways for activation of MAP kinase. Nature 143:651-653.

Barria A, Muller D, Derkach V, Griffith LC, Soderling TR (1997) Regulatory phosphorylation of AMPA-type glutamate receptors by CaM-KII during long-term potentiation. Science 276:2042-2045.

Bear MF, Malenka RC (1994) Synaptic plasticity: LTP and LTD. Curr Opin Neurobiol 4:389-399.

Bliss TVP, Collingridge GL (1993) A synaptic model of memory: longterm potentiation in the hippocampus. Nature 361:31-39.

Bornancin F, Parker PJ (1996) Phosphorylation of threonine 638 critically controls the dephosphorylation and inactivation of protein kinase $\mathrm{C} \alpha$. Curr Biol 6:1114-1123.

Bornancin F, Parker PJ (1997) Phosphorylation of protein kinase C- $\alpha$ on serine 657 controls the accumulation of active enzyme and contributes to its phosphatase-resistant state. J Biol Chem 272:3544-3549.

Bradford MM (1976) A rapid and sensitive method for the quantitation of microgram quantities of protein utilizing the principle of protein dye binding. Anal Biochem 72:248-254.
Cazaubon S, Bornancin F, Parker PJ (1994) Threonine-497 is a critical site for permissive activation of protein kinase $\alpha$. Biochem J 301:443-448.

Charriaut-Marlangue C, Otani S, Creuzt C, Ben-Ari Y, Loeb J (1991) Rapid activation of hippocampal casein kinase II during long-term potentiation. Proc Natl Acad Sci USA 88:10232-10236.

Chen C, Tonegawa S (1997) Molecular genetic analysis of synaptic plasticity, activity-dependent neural development, learning, and memory in the mammalian brain. Annu Rev Neurosci 20:157-184.

Doyère V, Errington ML, Laroche S, Bliss TVP (1996) Low-frequency trains of paired stimuli induce long-term depression in area CA1 but not in the dentate gyrus of the intact rat. Hippocampus 6:52-57.

Dutil EM, Keranen LM, DePaoli-Roach AA, Newton AC (1994) In vivo regulation of protein kinase $\mathrm{C}$ by trans-phosphorylation followed by autophosphorylation. J Biol Chem 269:29359-29362.

Edwards AS, Newton AC (1997) Phosphorylation at conserved carboxylterminal hydrophobic motif regulates the catalytic and regulatory domains of protein kinase C. J Biol Chem 272:18382-18390.

Edwards AS, Faux MC, Scott JD, Newton AC (1999) Carboxyl-terminal phosphorylation regulates the function and subcellular localization of protein kinase C $\beta$ II. J Biol Chem 274:6461-6468.

Feng X, Hannun YA (1998) An essential role for autophosphorylation in the dissociation of activated protein kinase $\mathrm{C}$ from the plasma membrane. J Biol Chem 273:26870-26874.

Fukunaga K, Stoppini L, Miyamoto E, Muller D (1993) Long-term potentiation is associated with increased activity of $\mathrm{Ca}^{2+} /$ calmodulindependent protein kinase II. J Biol Chem 268:7863-7867.

Gianotti C, Nunzi MG, Gispen WH, Corradetti R (1992) Phosphorylation of the presynaptic protein B-50 (GAP-43) is increased during electrically induced long-term potentiation. Neuron 8:843-848.

Gysin S, Imber R (1996) Replacement of Ser657 of protein kinase C- $\alpha$ by alanine leads to premature down regulation after phorbol-ester-induced translocation to the membrane. Eur J Biochem 240:747-750.

Hrabetova S, Sacktor TC (1996) Bidirectional regulation of protein kinase $\mathrm{M} \zeta$ in the maintenance of long-term potentiation and long-term depression. J Neurosci 16:5324-5333.

Ishizuka N, Weber J, Amaral DG (1990) Organization of intrahippocampal projections originating from CA3 pyramidal cells in the rat. J Comp Neurol 295:580-623.

Keranen LM, Dutil EM, Newton AC (1995) Protein kinase C is regulated in vivo by three functionally distinct phosphorylations. Curr Biol 5:1394-1403.

Klann E, Chen S-J, Sweatt JD (1991) Persistent protein kinase activation in the maintenance phase of long-term potentiation. J Biol Chem 266:24253-24256.

Klann E, Chen S-J, Sweatt JD (1993) Mechanism of protein kinase C activation during the induction and maintenance of long-term potentiation probed using a selective peptide substrate. Proc Natl Acad Sci USA 90:8337-8341.

Laurberg S (1979) Commissural and intrinsic connections of the rat hippocampus. J Comp Neurol 184:685-708.

Lee H, Kameyama K, Huganir RL, Bear MF (1998) NMDA induces long-term synaptic depression and dephosphorylation of the GluR1 subunit of AMPA receptors in hippocampus. Neuron 21:1151-1162.

Lee H-K, Barbarosie M, Kameyama K, Bear MF, Huganir RL (2000) Regulation of distinct AMPA receptor phosphorylation sites during bidirectional synaptic plasticity. Nature 405:955-959.

Lee JY, Hannun YA, Obeid LM (1996) Ceramide inactivates cellular protein kinase $\mathrm{C} \alpha$. J Biol Chem 271:13169-13174.

Lisman J (1994) The CaMKII hypothesis for the storage of synaptic memory. Trends Neurosci 17:406-412.

Lovinger DM, Akers RF, Nelson RB, Barnes CA, McNaughton BL, Routtenberg A (1985) A selective increase in phosphorylation of protein F1, a protein kinase $\mathrm{C}$ substrate, directly related to three day growth of long term synaptic enhancement. Brain Res 343:137-143.

Malenka RC (1994) Synaptic plasticity in the hippocampus: LTP and LTD. Cell 78:535-538.

Malenka RC, Kauer JA, Perkel DJ, Mauk MD, Kelly PT, Nicoll RA, Waxham MN (1989) An essential role for postsynaptic calmodulin and protein kinase activity in long-term potentiation. Nature 340:554-557.

Malinow R, Schulman H, Tsien RW (1988) Persistent protein kinase activity underlying long-term potentiation. Nature 335:821-824.

Malinow R, Schulman H, Tsien RW (1989) Inhibition of postsynaptic PKC or CaMKII blocks induction but not expression of LTP. Science 245:862-866.

Martin SJ, Grimwood PD, Morris RGM (2000) Synaptic plasticity: an evaluation of the hypothesis. Annu Rev Neurosci 23:649-711.

Mulkey RM, Herron CE, Malenka RC (1993) Essential role for protein phosphatases in hippocampal long-term depression. Science 261:1051-1055.

Mulkey RM, Endo S, Shenolikar S, Malenka RC (1994) Involvement of a calcineurin/inhibitor-1 phosphatase cascade in hippocampal long-term depression. Nature 369:486-488.

Nicoll RA, Oliet SHR, Malenka RC (1998) NMDA receptor-dependent and metabotropic glutamate receptor-dependent forms of long-term depression coexist in CA1 hippocampal pyramidal cells. Neurobiol Learn Mem 70:62-72.

Norman ED, Thiels E, Barrionuevo G, Klann E (2000) Long-term depression in the hippocampus in vivo is associated with protein phosphatase- 
dependent alterations in extracellular signal-regulated kinase. J Neurochem 74:192-198.

Oliet SHR, Malenka RC, Nicoll RA (1997) Two distinct forms of longterm depression coexist in CA1 hippocampal pyramidal cells. Neuron 18:969-982.

Orr WB, Newton AC (1994) Requirement for negative charge on "activation loop" of protein kinase C. J Biol Chem 269:27715-27718.

Osten P, Vlasamis L, Harris A, Sacktor TC (1996) Protein synthesisdependent formation of protein kinase $\mathrm{M} \zeta$ in long-term potentiation. J Neurosci 15:2444-2451.

Ramakers MJ, McNamara RK, Lenox RH, DeGraan PNE (1999) Differential changes in the phosphorylation of the protein kinase $\mathrm{C}$ substrates myristoylated alanine-rich $\mathrm{C}$ kinase substrate and growth-associated protein-43/B-50 following Schaffer collateral long-term potentiation and long-term depression. J Neurochem 73:2175-2183.

Roberson ED, English JD, Sweatt JD (1996) A biochemist's view of longterm potentiation. Learn Mem 3:1-24.

Roberson ED, English JD, Adams JP, Selcher JC, Kondratick C, Sweatt JD (1999) The mitogen-activated protein kinase cascade couples PKA and PKC to cAMP response element binding protein phosphorylation in area CA1 of hippocampus. J Neurosci 19:4337-4348.

Roche KW, O'Brien RJ, Mammen AL, Bernhardt J, Huganir RL (1996) Characterization of multiple phosphorylation sites on the AMPA receptor GluR1 subunit. Neuron 16:1179-1188.

Sacktor TC, Osten P, Valsamis H, Jiang X, Naik MU, Sablette E (1993) Persistent activation of the $\zeta$ isoform of protein kinase $\mathrm{C}$ in the maintenance of long-term potentiation. Proc Natl Acad Sci USA 90:8342-8346.
Schulman H (1994) Protein phosphorylation in neuronal plasticity and gene expression. Curr Opin Neurobiol 5:374-381.

Squire LR (1992) Memory and the hippocampus: A synthesis from findings with rats, monkeys, and humans. Psychol Rev 99:195-231.

Strack S, Barban MA, Wadzinski BE, Colbran RJ (1997) Differential inactivation of postsynaptic density-associated and soluble $\mathrm{Ca}^{2+} /$ calmodulin-dependent protein kinase II by protein phosphatases. J Neurochem 68:2119-2128.

Sweatt JD, Atkins CM, Johnson J, English JD, Roberson ED, Chen S-J, Newton AC, Klann E (1998) Protected-site phosphorylation of protein kinase $\mathrm{C}$ in hippocampal long-term potentiation. J Neurochem 71:1075-1085.

Thiels E, Barrionuevo G, Berger TW (1994) Excitatory stimulation during postsynaptic inhibition induces long-term depression in hippocampus in vivo. J Neurophysiol 72:3009-3016.

Thiels E, Norman ED, Barrionuevo G, Klann E (1998) Transient and persistent increases in protein phosphatase activity during long-term depression in the adult hippocampus in vivo. Neuroscience 86:1023-1029.

Wagner JJ, Alger BE (1995) GABAergic and developmental influences on homosynaptic LTD and depotentiation in rat hippocampus. J Neurosci 15:1577-1586.

Zhang J, Wang L, Schwartz J, Bond RW, Bishop WR (1994) Phosphorylation of $\mathrm{Thr}^{642}$ is an early event in the processing of newly synthesized protein kinase $C \beta_{1}$ and is essential for its activation. J Biol Chem 269:19578-19584. 